\title{
Experimental study on concrete damage location by Computerized tomography technology
}

Jinghong Liu

School of Civil Engineering, Tianjin University, Tianjin 300350, China; Hebei Construction group Co., Ltd, Baoding 071051, China; College of Urban and Rural Construction, Agricultural University of Hebei, Baoding 071001, China

liujinghongfree@sina.com (Corresponding author)

Jian Xie

School of Civil Engineering, Tianjin University, Tianjin 300350, China

Yongjian Liu

Hebei Construction group Co., Ltd, Baoding 071051, China

\section{Panfei Shi}

Anyang Architectural Design \& Research Institute, Anyang 455000, China

ABSTRACT. In order to solve the technical problem of damage localization in the concrete damage process, the Computerized Tomography (CT) scanning damage localization test was carried out under uniaxial compression. In addition to the three-dimensional meso model, the porosity variation law of concrete pore or cracks at different loading stages are obtained. A damage variable is created based on CT images. The results show that the change of porosity, pore volume and damage variable is consistent with the loading process. The rapid increase of concrete pore volume and damage variable can be the precursor of concrete damage. The whole process of the development and evolution of concrete cracks was observed and analyzed comprehensively by using the three-dimensional reconstruction images. A method for prognosist the evolution and localization of cracks in concrete by comprehensively analyze the $\mathrm{CT}$ reconstruction images, rapid increase of concrete pore volume and rapid growth of damage variable is presented.

KEYwords. Concrete; Three-Dimensional Meso Model; CT Test, Damage Location.

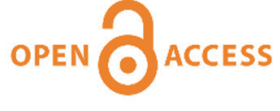

Citation: Liu, J., Xie, J., Liu, Y., Shi, P., Experimental study on concrete damage location by Computerized tomography and Acoustic Emission technology, Frattura ed Integrità Strutturale, 46 (2018) 352-360

Received: 03.08.2018

Accepted: 12.09 .2018

Published: 01.10 .2018

Copyright: (C) 2018 This is an open access article under the terms of the CC-BY 4.0, which permits unrestricted use, distribution, and reproduction in any medium, provided the original author and source are credited. 


\section{INTRODUCTION}

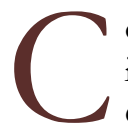

oncrete is a kind of complex multi-phase composite material, initial defects such as micro cracks and pores generate in concrete structure in the process of pouring for the reason of hydration heat release, shrink, etc. The micro cracks expand to macro-cracks under external load or environmental factors, then lead to the decline of the strength, stiffness and eventually cause stability damage to engineering. The relationship between the macro performance indexes and failure characteristic parameters has been a technical problem in various fields [1]. The current research of concrete is based on the conventional mechanics test method, that is speculate the mechanical character of structural materials through comparative analysis of test data instead of using the change of the internal meso structure directly to explain the damage evolution process under the load [2]. Computerized tomography technology (CT technology) can reach dynamic nondestructive observation on the change of internal meso structure in concrete material [3-6], and CT images are visual basic information to establish the meso damage model of concrete $[7,8]$. Degree of damage in concrete can be judged according to the tests, and this is of great significance to evaluate the concrete performance $[9,10]$.

The key of the research on concrete meso damage is to identify the existence of meso damage and the expand process of the damage effectively. CT is short as Computerized Tomography, compared with other methods, CT test has its incomparable advantage on nondestructive detection and real time observation in concrete material under various loading condition. CT images can be obtained by scanning the sections of concrete with industrial CT scanning. Both of the meso structure of concrete and its changing process can be analyzed through CT images, then the law of evolution and expansion for damage in concrete failure process is the key to the CT images analysis. Therefore, CT test is an effective mean to detect the meso pore structure, crack initiation, propagation and coalescence with no damage. In view of this, quite a lot of research work, from different views with different research methods, was done by scholars at home and abroad.

Foreign researches started quantitative study on concrete CT detection in 1980s. Morgan [11] is the first to use the medical CT to run CT scanning on concrete specimens, and concrete section images for aggregate, mortar, crack was obtained clearly. Chotard [12] got pretty effect on the change of the internal structure for cement while hydrating. Lawer [13] analyzed failure mode of concrete surface with digital image correlation technique, and the research conclusion could reflect the internal structural change during cracks evolution process, besides, the influence of aggregate shape, crack shape on concrete strength, toughness was discussed based on CT images after concrete cracking. Wong [14] conducted uniaxial compression CT test to normal and high strength concrete cylinder specimens, then the evolution process of pore under different stress state was studied. Meanwhile, a large number of concrete CT tests were carried out in China, and abundant research results were obtained: academician Chen Houqun using CT real time scanning to observe the meso failure process of concrete under the uniaxial compression, then the whole process CT images of internal meso cracks from initiation, expansion to coalescence was got, finally, quantitative analysis methods based on concrete CT images was established in the cracks area. Ding [15] used medical CT machine and special loading equipment to explore morphology change characteristics of micro cracks under the condition of different loading rate by images analyses and the distribution of CT number. Wu [16] described the damage property of concrete materials, and the failure process in concrete was revealed in meso view, that are Initial crack stress and crack propagation process. Liu [17] used CT technique to scan concrete specimens, then reconstructed the images with Mimics software, finally the 3D geometric model of concrete specimens can be got. The plastic damage model of concrete 3D numerical specimens was introduced to simulate the uniaxial tension and compression loading process, then the rationality of $3 \mathrm{D}$ numerical model was identified.

Although researchers at homeland and abroad have done much research work based on CT test [18-22], it is rare to see do quantitative analysis on crack initiation and propagation mechanism of concrete by using acoustic emission and CT combined. CT scanning have obvious advantage on real-time and nondestructive detection to internal structural change process, but its disadvantage is for both of the equipment and scanning cost are much higher. The previous real-time monitoring tests are carried out CT scanning after stopping loading when the loading reaches a specific stress stage. The test results may not ideal or the cost may increase if the stresses when scanning are not properly selected. As the unique passive detection technology in nondestructive testing, acoustic emission detection technology can monitor and evaluate the whole concrete structure in real-time, acoustic emission signal can reflect the change situation of the internal structural damage accurately except for its defects that can't be observed evolution of pore and damage in structures directly. Considering their advantages in detection, tests on combination of acoustic emission and CT can be conducted. Stop loading when acoustic emission signal prompts there are new cracks generated or the old cracks expanded, then explore the relationship between CT scanning images and acoustic emission by scanning concrete with CT.

In this thesis, the meso structure of concrete and its changing process was analyzed with the feature of CT images, then the order of damage evolution in concrete is described by damage variable based on CT images. 


\section{CT DAMAGE LOCATION TEST IN CONCRETE UNDER UNIAXIAL COMPRESSION}

he process of cracks propagation was observed with X-ray CT scan detection system in State Key Laboratory of coal mining, China University of Mining and Technology (Beijing), 3000kN ultra high rigidity servo testing machine under uniaxial compression, the schematic diagram of the test system is shown in Fig. 1.

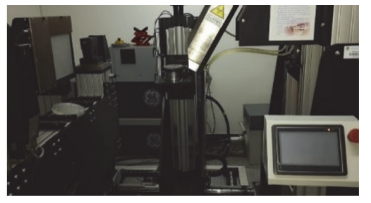

CT scanning system

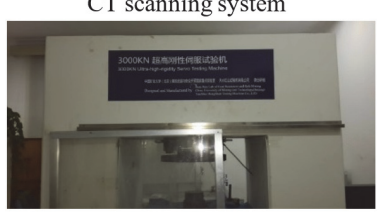

High rigidity servo tester of $3000 \mathrm{kN}$

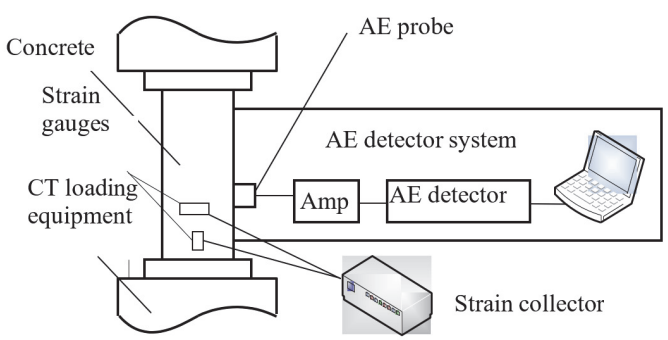

Figure 1: Sketch of experimental system.

Different amount air entrained agent was added when making concrete blocks, then 4 groups concrete specimens, with initial porosity of $1.1 \%, 3.3 \%, 6.7 \%$ and $9.2 \%$, were obtained to utilize in this test. The hight and the radium of the concrete cylinder blocks are $190 \mathrm{~mm}, 50 \mathrm{~mm}$. The mix proportion of concrete specimens used in the test is shown in Tab. 1.

\begin{tabular}{cccc}
\hline \multicolumn{4}{c}{ The amount of materials in per cube meters concrete } \\
Cement $(\mathrm{kg})$ & Water $(\mathrm{kg})$ & Sand $(\mathrm{kg})$ & Coarse aggregate $(\mathrm{kg})$ \\
327 & 189 & 755 & 1133 \\
\hline
\end{tabular}

Table 1: Mix proportion of concrete specimens in test.

Displacement control methods was used in the test and its laoding rate was $0.2 \mathrm{~mm} / \mathrm{min}$. The scanning work was done in the range of upper $100 \mathrm{~mm}$, and it is needed add that the scanning interval is $0.2 \mathrm{~mm}$. Repeat the work like this until test specimens reach the peak strength. Continue with the loading after the scanning. The loading curve of the test is shown in Fig. 2. The acoustic emission machine was introduced to collect the test data in the whole loading process.

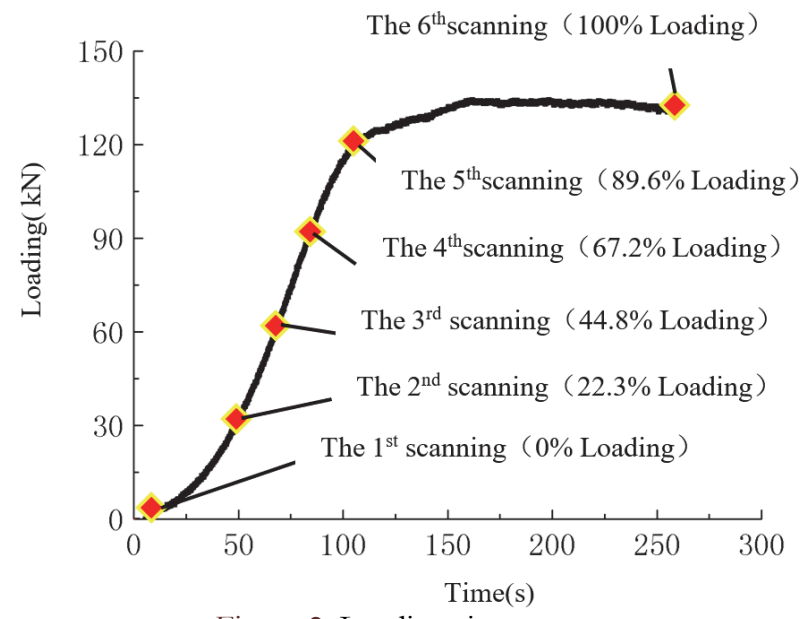

Figure 2: Loading-time curve.

As shown in Fig. 2, 5 cyclic loading tests were carried out on concrete test specimens, and the loading interval was $30 \mathrm{KN}$ in every two adjacent loads, finally the ultimate strength was $134 \mathrm{KN}$. 
There are 6 stages of scanning on concrete test specimens, included the initial stage, as shown in Tab. 2.

\begin{tabular}{ccc}
\hline CT scan times & Loading $(\mathrm{kN})$ & Percent of the peak strength \\
$1^{\text {st }}$ scan & 0 & $0 \%$ \\
$2^{\text {nd }} \operatorname{scan}$ & 30 & $22.3 \%$ \\
$3^{\text {td }}$ scan & 60 & $44.8 \%$ \\
$4^{\text {th }}$ scan & 90 & $67.2 \%$ \\
$5^{\text {th }}$ scan & 120 & $89.6 \%$ \\
$6^{\text {th }}$ scan & 134 & $100 \%$ \\
\hline
\end{tabular}

Table 2: The load corresponding to the six scanning time of the concrete specimen.

There are 499 CT scanning images in every test specimen, 5 CT scanning images are chosen to conduct the analysis due to the limited space, as shown in Fig. 3.

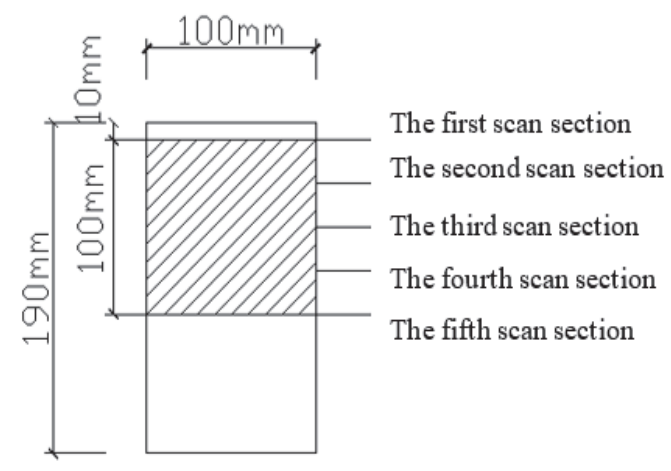

Figure 3: Concrete sections map of CT scan.

CT scanning test and acoustic emission test were conducted in 4 groups concrete test specimens under uniaxial compression, then the load-time curve, CT images and acoustic emission parameters were collected during the loading process. The concrete test specimens with initial $9.2 \%$ porosity are chosen to analyze in this thesis as the limited space. The CT scanning images of initial state, $30 \mathrm{kN}, 60 \mathrm{kN}, 90 \mathrm{kN}, 120 \mathrm{kN}$, and $134 \mathrm{kN}$ when destroyed are listed in Fig. 4.
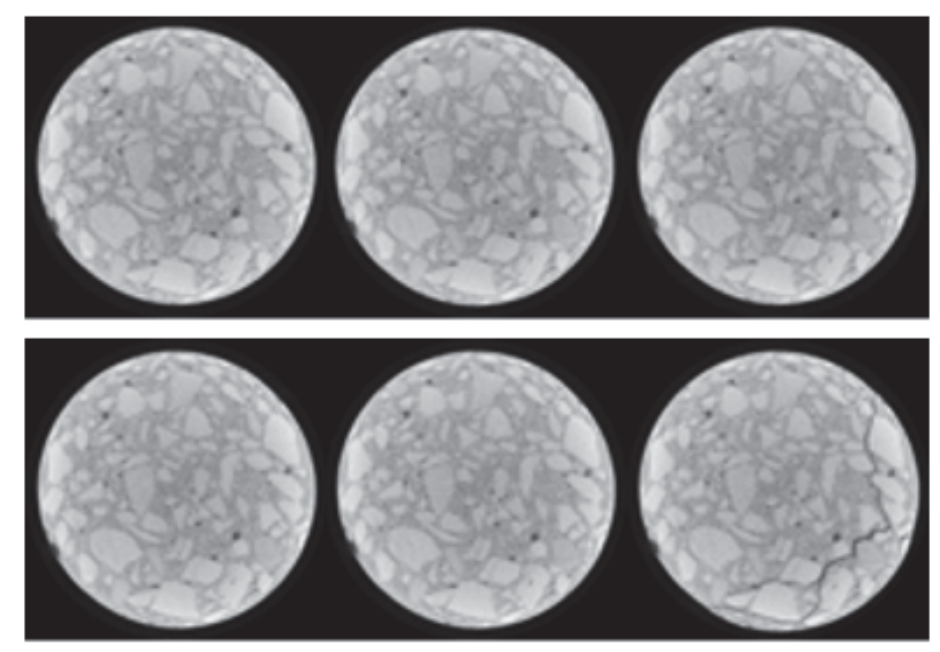

Figure 4: CT scanning images of concrete in different loading.

As shown in Fig. 4, there is no obvious cracks during the early loading stages in test specimens with $9.2 \%$ initial porosity, and the early loading stages can be considered as a compaction process for the pores for the reason of its relative large porosity. The internal micro cracks connect with micro pore and eventually the main visible cracks generate until the test specimens are destroyed. 


\section{D MESO SCALE MODEL OF CONCRETE CT IMAGE}

he Amira software was used to reconstruct the meso structure in 3D after the CT images were divided [13]. It is needed to say that Amira is a 3D visual modeling software system, and two basic components of the system, data and modules with different function, are included. The data are processed with modules by their connection with each other, then the visualization of scientific data can be realized in various application area, such as medical science, materials science, geophysics and engineering etc. The result of the 3D reconstruction shows in Fig. 5.
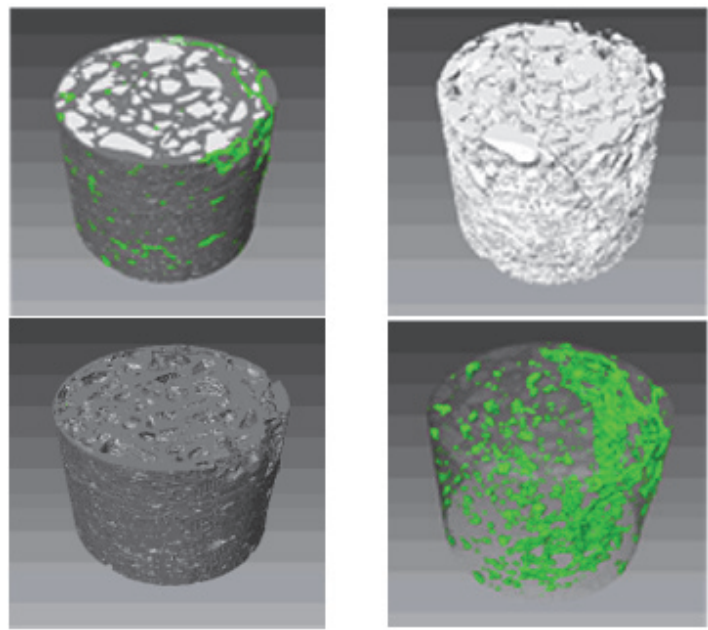

Figure 5: From left to right: test specimens, aggregate, mortar, spatial distribution of cracks.

In Fig. 5, the distribution of aggregate in concrete 3D reconstruction model accords with the original CT images, and the volume of each component is almost the same with the mix proportion of concrete. The visualization of cracks realizes with transparent processing, and the spatial shape is relatively clear, finally the cracks structure in concrete materials is shown in a real way.

Subsequent work like image segmentation and extrusion of cracks can be done with Amira Software, and the Fig. 6 is the characteristic change chart of cracks and pores.

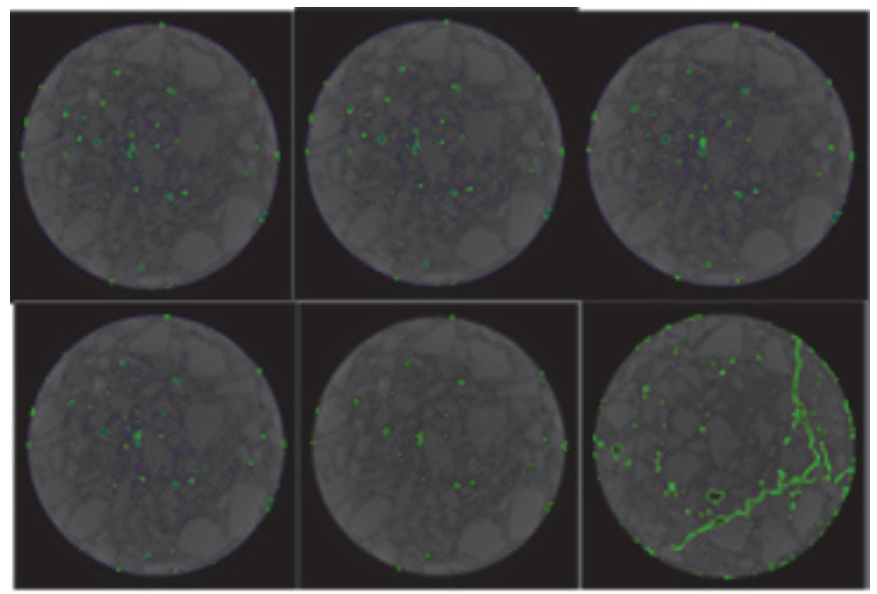

Figure 6: Threshold segmentation map of Concrete pore under different scanning stage

As shown in Fig. 6, there are cracks and pores in concrete surrounded by green area, then the cracks and pores show more clear in CT images through segmentation and extrusion. CT images in the upper of the test specimens from the 20th to 470th CT images were selected to gather statistical information on the volume of pores and the porosity in every 90 CT images, the relation graphs of pore volume, Pore ratio with pressure can be seen in Fig. 7, Fig. 8. 


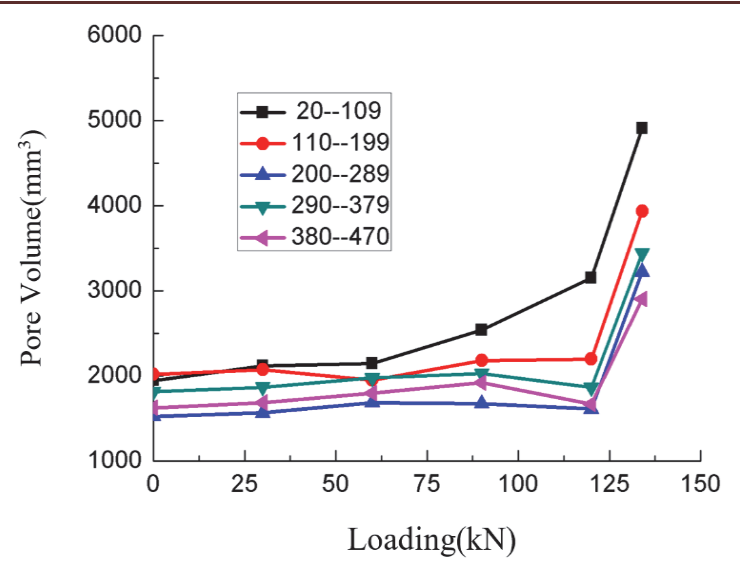

Figure 7: Pore volume-pressure map.

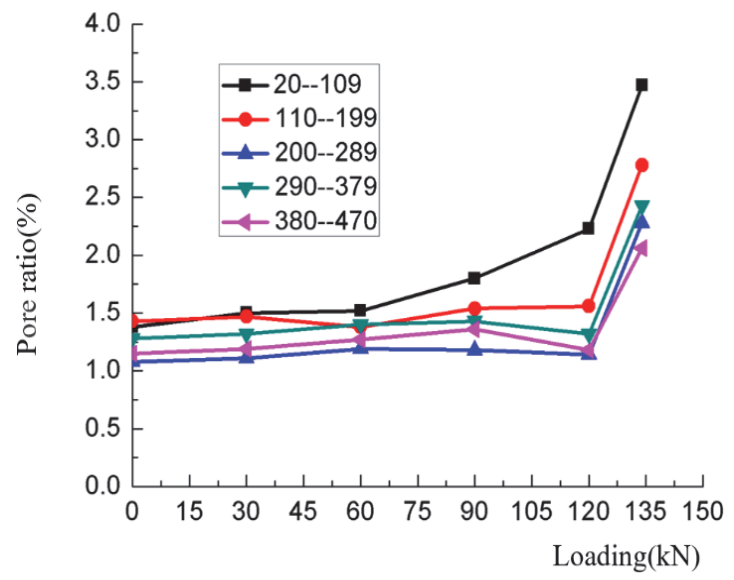

Figure 8: Pore ratio change with loading.

In Fig. 7 and Fig. 8, The changing law of pore volume, porosity with loading in every CT scanning pieces is almost the same under uniaxial loading. The loading curve decreases slight in the start loading stage but keeps nearly a straight line, as a result that the test specimens is in the elastic stage. In this stage, initial pores are compressed then the volume of the pores and porosity reduce. With the increment of the load, the micro cracks expand gradually, certainly, the volume of the pores enlarge. When the load approaches the peak strength, there are obvious cracks in test specimens from CT images, then the volume of pores and porosity achieve the maximum, thus, the phenomenon that the rapid increment of the volume of pores and porosity indicates the failure of concrete test specimens.

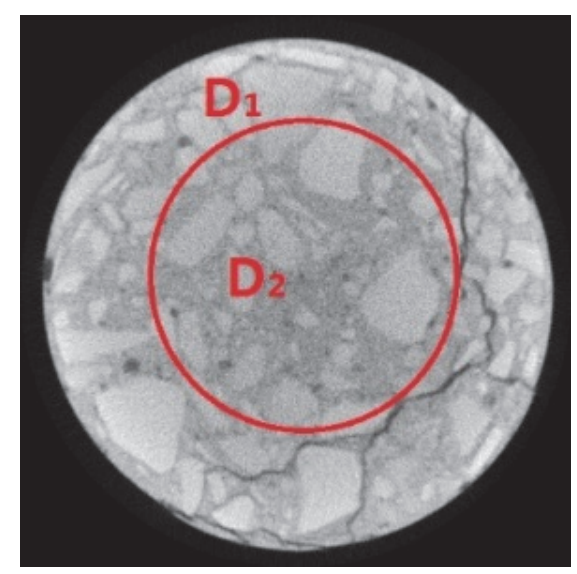

Figure 9: Concrete damage area schematic diagram 


\section{DAMAGE ANALYSIS DURING THE CONCRETE LOADING PROCESS}

he concrete's effective area is calculated by determining the undamaged area of the center in concrete's CT image, shown as $\mathrm{D}_{2}$ in Fig. 9. The remaining part is considered to be a damaged component and is designated as $\mathrm{D}_{1}$. The definition of damage variable is $H=D_{1} / D_{2}$. The load damage curves of concrete specimens are shown in Fig. 10.

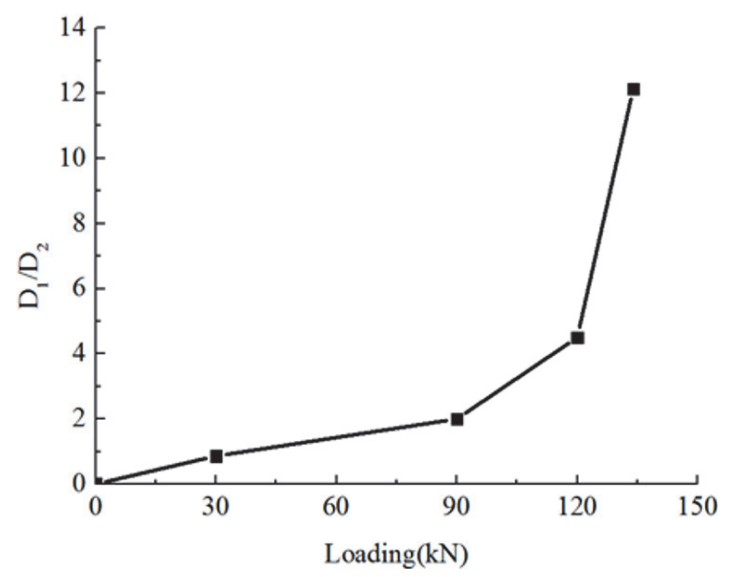

Figure 10: Loading-damage curve of concrete specimen.

$\mathrm{D}_{1}$ and $\mathrm{D}_{2}$ are determined by analyzing the crack and damage distribution on the cross sections of concrete's CT image. A concentric circle is drawn on the cross section of $50 \mathrm{~mm}$. The damage was detected by Acoustic Emission and verified by CT image. The degree of damage is measured by the density of the damage points. D1 is determined if a damage point in a circle is less than a threshold. If the crack passes through the center of the section, this method is invalid, but this situation is very rare.

As shown in Fig. 10, the damage points, based on the damage variable of CT images and acoustic emission damage location, in the main cracks area after destruction were compared with the damage points in other area, then the result showed the order of the concrete test specimens. Before $30 \%$ of the peak load, the damage variable is less than 1 which indicates the damage location is in disorder; When the load reach $80 \% \sim 100 \%$ of the peak load, the damage curve rises steeply, then the cracks appears, finally, the test specimens instability fails. The loading-damage curve reflects the whole process from disorder to order, and it keeps in pace with press-porosity volume cure. Though the comprehensive analysis on damage location map with acoustic emission, press-porosity volume cure and the load-time curve, that fact can be get as follows. Before $30 \%$ of the peak load, the damage points are disordered, and the damage variable in concrete is relatively small, then the volume of the pores in material increase slightly. After the load is steadily increase to $30 \%$ of the peak load, the damage points appear in order around the macro failure surface, then the damage variable start to grow, so do the volume of the pores. The change of the pores distribution and the center coordinate are also not obvious, and all of this phenomena indicate that the test specimens are destroying steadily. When the load reaches the peak, the stress of concrete test specimen is almost unchanged, while the damage points around the macro failure surface increase rapidly. The damage variable and the volume of the pores show a marked trend of growth.

\section{CONCLUSION}

(1) The CT reconstruction images, rapid increase of concrete pore volume and rapid growth of damage variable are used comprehensively to prognosist the evolution and localization of cracks in concrete provides a new method for the concrete analyses on the evolution process of cracks and damage location.

(2) The damage variable is established based on CT images and CT images' damage points; then the set of the 3D meso model supplement the traditional stochastic mathematical model in concrete. The 3D model set reflects the relationship between meso structure in concrete and macro characteristics, and this lay foundation to the concrete research on damage mechanism. 
(3) The damage variable is less than 1 indicating that the damage is very small randomly distributed before $30 \%$ of the peak load. The loading-damage curve increases steadily between $30 \%$ and $80 \%$ of the peak load, indicating that the damage is orderly changed. When the load reaches $80 \%$ of the peak load, the damage variable increases sharply, and the test specimen fails at this stage. The load-damage curve shows the whole failure process consistent with the load-pore volume curve.

(4) The rapid increment of the pore volume, porosity and damage variable can be regarded as the destroy of concrete test specimens, therefore, the phenomenon can be a sign of the destroy in concrete.

\section{ACKNOWLEDGEMENTS}

his paper is supported by the Key Fund Project program sponsored by the Education Department of Hebei Province (ZD2014073). Tremendous thanks to several colleagues and graduate students for their support during the various stages of the work summarized here.

\section{REFERENCES}

[1] Dang, F.N., Lei, G.y. and Ding, W.H. (2015). Study on the CT meso-test experiment of static and dynamic failure processes of concrete, Journal of Hydroelectric Engineering, 34(1), pp. 189-196.

[2] Liu, M.J., Zhao, J. and Wang, G.W. (2014). Microscopic study of damage in carbonated concrete based on computerized tomography, Journal of Guangxi University: Nat Sci Ed., 39(1), pp. 187-193.

[3] Liu, J.H., Jiang, Y.D. and Zhao, Y.X. (2012). Fractal Description of Coal Damage Process Based on CT Image, Journal of Beijing Institute of Technology, 32(12), pp. 1219-1222.

[4] Bossa, N., Chaurand, P. and Vicente, J. (2015). Micro-and nano-X-ray computed-tomography: A step forward in the characterization of the pore network of a leached cement paste, Journal of Cement and Concrete Research, 67, pp. 138147.

[5] Kocur, G.K., Saenger, E.H. and Vogel, T. (2010). Elastic wave propagation in a segmented X -ray computed tomography model of a concrete specimen, Construction and Building Materials, 24(12), 2393 -2400.

[6] Mao, L.T., Sun, Q.W. and Yuan, Z.X. (2016). Crack and strain field analysis in the concrete under uniaxial compression based on CT images, Journal of Building Materials, 19(3), pp. 449-4555.

[7] Tekin, I., Birgul, R. and Yaman, I.O. (2015). Monitoring macro voids in mortars by computerized tomography method, Journal of Measurement, 63, pp. 299-308.

[8] Lockner, D. (1993). The role of acoustic emission in the study of rock fracture, Int. J. Rock Mech. Min. Sci., 30(7), pp. 883-899.

[9] Lai, Y.S., Xiong, Y. and Cheng, L.F. (2015). Study of Chatacteris of Acoustic Emission During Entire Loading Tests of Concrete and Its Application, Journal of Building Materials, 18(3), pp.380-386.

[10] Wang, J.Y., Dewanckele, J. and Cnudde, V. (2014). X-ray computed tomography proof of bacterial-based self-healing in concrete, Journal of Cement \& Concrete Composites, 53, pp. 289-304.

[11] Morgan, I.L., Ellinger, H. and Klinksiek, R. (1980). Examination of concrete by computerized tomography, ACI Journal, 77(1), pp. 23-27.

[12] Chotard, T.J., Boncoeur-Martel, M.P. and Smith, A. (2003). Application of X-ray computed tomography to characterize the early hydration of calcium aluminates cement, Cement \& Concrete Composites, 25(1), pp. 145-152.

[13] Lawer, J.S., Keane, D.T. and Shah, S.P. (2001). Measuring three-dimensional damage in concrete under compression, ACI Materials Journal, 98(6), p. 465-475.

[14] Wong, R.C.K. and Chau, K.T. (2004). Estimation of air void and aggregate spatial distributions in concrete under uniaxial compression using computer tomography scanning, Cement and Concrete Research, 35, pp.1566-1576.

[15] Ding, W.H., Chen, H.Q. and Zhang, J.J. (2006). X Ray CT observation on the fracture process under high strain rate, Journal of architectural structure, (S2), pp. 758-762.

[16] Wu, L.Q. (2006). The meso scale test research on concrete under uniaxial compression, Nan Ning: Guang Xi University.

[17] Liu, H.K. and Li, J. (2014). Nonlocal meso damage model in concrete under uniaxial tension, Journal of Tongji University (Natural Science Edition), (2), pp. 203-209.

[18] Mao, L.T., Lian, X.Y. and Hao, L.N. (2014). Fractal calculation of 3D cracks based on digital volumetric images and its application, Journal of China University of Mining \& Technology, 43(6), pp. 1134-1139. 
[19] Bossa, N., Chaurand, P. and Vicente, J., (2015). Micro-and nano-X-ray computed-tomography: A step forward in the characterization of the pore network of a leached cement paste, Journal of Cement and Concrete Research, 67, pp. 138147.

[20] Liu, J.H., Jiang, Y.D., Zhu, J. and Han, W. (2013). Fractal Characteristics of Coal Uniaxial Compression Acoustic emission Tests, Journal of Beijing Institute of Technology, 33(4), pp. 335-338.

[21] Wang, W., Liu, J.H. and Shi, P.F. (2015). The Fractal Analysis of the Rock Meso Rupture Process Based on CT Technology[], Journal of Agricultural University of Hebei, 38(3), pp. 124-127.

[22] Shi, P.F., Liu, J.H., Yang, Y.F. and Gao, Y. (2016). Fractal feature of different initial damage concrete under the uniaxial compression test, Concrete, (4), pp. 39-42. 